\title{
A comparison of erythrocyte sedimentation rates of bloods anticoagulated with trisodium citrate and EDTA among TB presumptive patients at the University of Gondar comprehensive specialized hospital, northwest Ethiopia
}

Zegeye Getaneh ( $\square$ zegeyegetaneh91@gmail.com )

University of Gondar College of Medicine and Health Sciences https://orcid.org/0000-0002-8239-8491

Fekadu Ayelgn

University of Gondar College of Social Sciences and Humanities

\section{Geletaw Asemahegn}

University of Gondar

Habtamu Geleta

University of Gondar

Aregawi Yalew

University of Gondar College of Medicine and Health Sciences

Tadele Melak

University of Gondar College of Medicine and Health Sciences

\section{Research note}

Keywords: Erythrocyte sedimentation rate, EDTA, Tri-sodium citrate, Westergren Method, Comparison

Posted Date: February 11th, 2020

DOI: https://doi.org/10.21203/rs.2.16918/v3

License: (c) (i) This work is licensed under a Creative Commons Attribution 4.0 International License. Read Full License

Version of Record: A version of this preprint was published at BMC Research Notes on February 27th, 2020. See the published version at https://doi.org/10.1186/s13104-020-04963-0. 


\section{Abstract}

Objective: The purpose of this study was comparing the erythrocyte sedimentation rate (ESR) results of trisodium citrate (TSC) and ethylene diamine tetra-acetic acid (EDTA) anticoagulants. A comparative cross-sectional study was conducted at the University of Gondar specialized referral hospital, northwest, Ethiopia. A total of 70 TB presumptive participants were recruited. From each of the 70 participants of the study, 3 and $1.6 \mathrm{ml}$ of blood was collected in EDTA tubes and $0.4 \mathrm{ml}$ of trisodium Citrate anticoagulant containing test tubes, respectively. Results: The mean \pm SD values of ESR were $57.9 \pm 41.45 \mathrm{~mm} / \mathrm{hr}$ in EDTA and $50.99 \pm 43.5 \mathrm{~mm} / \mathrm{hr}$ in TSC anticoagulated blood. The mean difference of ESR values between EDTA and TSC blood $(6.91 \pm 13.66 \mathrm{~mm} / \mathrm{hr})$ was statistically significant. The Mean \pm SD of ESR values using EDTA and TSC in males were $59.57 \pm 42.31$ and $53.57 \pm 44.61 \mathrm{~mm} / \mathrm{hr}$ while for females it was $54.71 \pm 40.44$ and $46.04 \pm 41.82 \mathrm{~mm} / \mathrm{hr}$, respectively. The study indicated that there was a significant difference between ESR values with EDTA and tri-sodium citrate anticoagulants. Keywords: Erythrocyte sedimentation rate, EDTA, Tri-sodium citrate, Westergren Method, Comparison

\section{Introduction}

Erythrocyte sedimentation rate (ESR) is a common inexpensive, sensitive and non-specific hematology test frequently ordered in clinical medicine. It is the most widely used laboratory test for evaluating and monitoring the courses of infections, acute phase inflammation, autoimmune and malignant diseases. In addition, it serves as a general sickness index when it is used in conjunction with patient's clinical history and physical examinations (1-6).

Increased amounts of the plasma proteins, like fibrinogen are the major factors which increase ESR test results by reducing the negative electrostatic force among red blood cells (RBCs), leading to an increased rate of rouleaux formation and the easy falling down of RBCs within plasma $(7,8)$. In cases of inflammatory and infectious processes, fibrinogen concentration in the blood increases rouleaux formation and RBCs settle faster than normal $(9,10)$.

An elevated ESR is often observed in cases of infectious diseases (Tuberculosis (TB), bone and severe skin infections), malignancy, inflammatory or destructive processes, auto immune diseases and rheumatic fever (11-13). As well as in collagen vascular and infective endocarditic diseases $(12,13)$. It is also important for the assessment of the severity of inflammatory bowel diseases in children (14-17) and marking responses to the treatment of TB $(18,19)$. Moreover, an increased ESR can be an early predictive marker of HIV seropositive progression towards AIDS $(20,21)$. Besides, increased ESR can also be used as an inexpensive "sickness index" in the elderly (22).

A raised result of ESR is observed in a wide range of infectious, inflammatory, generative and malignant conditions and associated occurrences, like anemia, pregnancy, hemoglobinopathies, hemoconcentration and the treatment of anti-inflammatory drugs which change plasma proteins that increase in fibrinogen, immunoglobulin, and C-reactive protein $(23,24)$. 
The principle of the ESR determination is based on the measurements of sedimentation rates of aggregated erythrocytes in plasma. The International Council for Standardization in Hematology (ICSH) recommended the Westergren method as a choice for ESR determination. When anticoagulated blood is placed in a Westergren tube in vertical column, the erythrocytes normally settle quite slowly by the influence of gravity, and the distance of erythrocytes falls down in a vertical column from the plasma in within one hour will be taken as ESR value (25-27).

For ESR determination, blood anticoagulated with 3.8\% trisodium citrate (TSC) or ethylene diamine tetra acetic acid (EDTA) can used. Using undiluted blood anticoagulated with K3EDTA is a recommended specimen for ESR determination by ICSH because it gives a more reliable result than the traditional TSC $(21,28)$ by reducing the risk of pre-analytic mistakes due to a partially coagulated specimen or small clots, an altered blood/trisodium citrate (TSC) ratio, and problems linked to the final volume, inherent mainly in techniques using special tubes for both specimen collection and ESR measurement $(25,26)$. However, according to the 2011 ICSH recommendations, the reference method for the measurement of the ESR should be based on the Westergren method with modifications that use either whole blood anticoagulated with EDTA and later diluted with TSC or saline or whole blood anticoagulated with TSC in a 4:1 datution ratio in Westergren pipettes (29).

Despite the fact that the ESR test is one of the commonest investigations carried out in the clinical hematology laboratories, there has been no recognized standard control sample for monitoring the test.

The reliability and reproducibility of the results depends on the use of correct methodologies. Although, a variety of research was conducted on a matters relating to ESR values of different diseases, no attempts were made to compare the ESR values of blood mixed with TSC and EDTA in the study area. So, this study aimed to assess the variability of ESR values of the two commonly used anticoagulants in individuals suffering from presumptive TB.

\section{Methods And Materials}

\section{Study setting and population}

A comparative cross-sectional study was conducted on a total of 70 study subjects who visited the TB Clinic at the University of Gondar comprehensive specialized hospital (UOGCSH) from March to May 2018. UOGCSH is found in Gondar town, Amhara regional state, northwest Ethiopia. Gondar town is located at $727 \mathrm{~km}$ from Addis Ababa and $185 \mathrm{~km}$ from Bahir Dar town and situated at a latitude and longitude of $12^{\circ} 36^{\prime} \mathrm{N}$ and $37^{\circ} 28^{\prime} \mathrm{E}$, respectively, with an elevation of 2133 meters above sea level (30) to the north western part of Ethiopia.

All patients aged 15 years and above and willing to participate in the study were included. Patients who did not give enough amounts of blood sample and unwilling to take part were excluded.

\section{Sample size determination}


A total of 70 participants were recruited for this comparative cross-sectional study. The double population mean formula was used to calculate the required sample size using the mean and standard deviation (SD) of TSC and EDTA taken from other studies (31) with $80 \%$ power $(0.84)$ and $95 \%$ level of significance (1.96).

\section{Data collection and ESR determination}

The questionnaire and check lists were prepared in the English language and translated to Amharic, the local language were used to collect socio-demographic and clinical data. Patient blood was collected in K3EDTA tubes (BD Vacutainer ${ }^{\circledR}$ Glass Tubes) and TSC tubes (BD Vacutainer ESR glass tube). Five ml of venous blood was collected from each participant in K3EDTA and TSC tubes. The TSC blood collection tube contained $3.8 \%$ of TSC and that of EDTA contained $8.0 \mathrm{mg}$ of EDTA in it. Then $1.6 \mathrm{ml}$ of the whole blood sample was added to the $0.4 \mathrm{ml}$ of $3.8 \%$ TSC solution, and $3.0 \mathrm{ml}$ of blood was added to EDTA tube and immediately mixed by inverting the tubes three times. Then ESR values were measured by the Westergren method. For each participant, two tests of ESR determination were performed from each tube within 2 hours in accordance with the ICSH recommendation (29). We filled the Westergren tube to exactly "0"mark and placed the tube in the rack for 1 hour, and ESR results were recorded in $\mathrm{mm} / \mathrm{h}$. Finally, results obtained from K3EDTA samples were compared to those of TSC samples.

\section{Quality assurance}

Standard operating procedures (SOPs) and manufacturers' instructions were strictly followed for all laboratory activities as much as possible. All blood collection test tubes were checked for expiry dates, and laboratory results were recorded on standard report formats using participant identification number. The data of each patient were reviewed for mislabeling and completeness.

\section{Data analysis}

Epilnfo version 3.5.4 was used for data entry and SPSS version 20 for analysis. In this study, we used the paired t-test to determine significant differences between whole blood anticoagulated using EDTA and TSC for ESR determination. The mean was used since it is the basis for all statistical computations, and SD was obtained to aid the computation of the t-value to measure the average amount of scatter in a distribution. To establish the relationship between the 2 methods, comparison studies were analyzed by simple least squares linear regression and Pearson's correlation coefficient to obtain the $y$-intercept, the slope, and the SD of the regression line (Sy/x). The data were compared by the Bland-Altman analysis (32). Paired sample t-test at $95 \%$ confidence level was used to compare the two methods, and in all cases P-values $<0.05$ were considered as statistically significant.

\section{Results}

\section{Socio-demographic information}


A total of 70 TB presumptive patients aged from 15 to 82 years were included in the study. The majority, $46(65.7 \%)$, of the participants were male and lived in rural areas; $21(30 \%)$ were in the age range of 36-50 years (Table 1).

\section{Comparison of ESR values}

The Mean \pm SD ESR values of patients according to EDTA and TSC anticoagulated blood were $57.9 \pm$ 41.45 and $50.99 \pm 43.5 \mathrm{~mm} / \mathrm{hr}$, respectively. The ESRs value obtained from EDTA blood were higher than TSC blood for all independent variables. The mean \pm SD of ESR value in males using EDTA and TSC blood was $59.57 \pm 42.31$ and $54.71 \pm 40.44 \mathrm{~mm} / \mathrm{hr}$ while for females it was $53.57 \pm 44.61$ and $46.04 \pm 41.82$ $\mathrm{mm} / \mathrm{hr}$ (Table 2).

The paired sample t-test analysis showed that there was a statistically significant difference between the mean \pm SD of ESR values of the two anticoagulated blood. The mean difference of ESR values between the use of EDTA and TSC anticoagulated blood was $6.91 \pm 13.66 \mathrm{~mm} / \mathrm{hr}$ with a t-value of $4.24(\mathrm{P}<$ $0.0001 ; 95 \% \mathrm{Cl}: 3.66$ - 10.17). The computed t-value (4.24) was greater than the tabulated or critical tvalue (1.667) at 69 degree of freedom and $95 \%$ level of significance. Therefore, there was a significant difference between the use of EDTA and TSC as anticoagulants for ESR determination (Add. Table).

The Bland-Altman data analysis showed no systematic bias, and $95 \%$ of all samples fell into the narrow $95 \%$ limits of agreement $(d-1.96 S D=6.914-[2 \times 13.661]=-20.408$ and $d+1.96 S D=6.914+[2 \times 13.661]=$ +34.236) (Figure 1). A linear regression analysis showed a satisfactory correlation between the two methods $\left(\mathrm{r}=0.949, P<0.001 ; \mathrm{r}^{2}=0.901 ; \mathrm{y}=11.769+0.949 x ;\right.$ and $\left.\mathrm{Sy} / \mathrm{x}=13.106\right)$ (Add. Figure).

\section{Discussion}

Although ESR is not a specific marker of inflammation, currently it is frequently used in the diagnosis and evaluation or monitoring of patients with chronic diseases (33). The ESR value obtained from this comparison showed that the mean value of EDTA anticoagulated blood $(57.90 \mathrm{~mm} / \mathrm{hr}$ ) was greater than that of TSC blood $(50.99 \mathrm{~mm} / \mathrm{hr}$ ) by $6.91 \mathrm{~mm} / \mathrm{hr}$. This may be because EDTA increases rouleaux formation more than TSC, leading to increases in ESR in EDTA blood, or it might be due to a difference in viscosity, where citrated blood may be less viscous than EDTA blood resulting in lower ESR values (3436). This observation corresponds to the result reported from Tehran University, Iran, and stated that there was a significant difference between the results of ESR tests which used two anticoagulants (37).

The result of our study was similar to that of a study conducted in Nigeria whose final finding stated that the mean \pm SD ESR value of EDTA anticoagulated blood was higher than the mean \pm SD ESR value of the TSC. When compared to our finding, the result of the Nigerian study was within the normal range of ESR. The reason for the difference was that their study was conducted on healthy individuals, while ours was conducted on presumed TB patients which increased the ESR value. In addition, the mean \pm SD ESR values of males were less than those of females, contradicting the finding. This might be due to the fact that most of our male participants were old and had history of TB (31). 
However, the result of our study differed from what was reported in India and stated that ESR measurement values of citrated blood were greater by $4-6 \mathrm{~mm} / \mathrm{hr}$ than those of EDTA (10). Our result also differed from that of a study conducted at Yenepoya University hospital, India. They found that the values of ESR that utilized EDTA was $4-6 \mathrm{~mm} / \mathrm{hr}$ less than values that used TSC. The authors recommended that ESR be performed using EDTA blood instead of TSC since the former utilizes only a limited amount of blood for the procedure (9). Another study done in the Philippines found a mean ESR value of 36.7 and 43.09 for EDTA and TSC, respectively. These differed from our findings, perhaps because of some physiological and genetic differences between white and black people (38).

\section{Conclusion}

The average ESR value among participants of UoGCSH using EDTA and TSC blood were 57.90 and 50.99, respectively. The ESR value the value of EDTA anticoagulated blood was greater than that of TSC blood with a mean difference of 6.91. The computed t-value (4.2.) is greater than the tabulated t-value therefore there is a significant difference between the use of EDTA and TSC as anticoagulant for ESR determination." Therefore, laboratories using EDTA and TSC for ESR determination should have different reference values for each anticoagulant if the observed findings are confirmed in healthy population and among sick individuals.

\section{Limitations}

The study was not only limited to a single district but also dealt with just presumed TB patients. Therefore, the result of this research may not be representative for the whole population.

\section{Abbreviations}

CBC: Complete blood count; EDTA: Ethylene diamine tetra acetic acid; ESR: Erythrocyte sedimentation rate; UoGCSH: University of Gondar Comprehensive Specialized Hospital; ICSH: International council for standardization in hematology; $\mathrm{K}_{3}$ EDTA: Tri potassium ethylene diamine tetra acetic acid; $\mathrm{mm} / \mathrm{hr}$. millimeter per hour; NCCLS: National committee for clinical laboratory standards; RBC: Red blood cells; SD: Standard deviation; TB: Tuberculosis; TSC: Trisodium citrate

\section{Declarations}

\section{Ethics approval and consent to participate}

Ethical clearance was obtained from School of Biomedical and Laboratory Sciences Research and Ethical Review Committee. Permission letter was obtained from the hospital director to conduct the study. The objectives of the research were explained to the study participants and written informed consent was taken. To ensure confidentiality of data, participants were identified using codes.

\section{Consent to publish}


Not applicable.

\section{Availability of data and materials}

All the data on which the conclusions of this manuscript are drawn are available in the corresponding author. So that any who needs the data can get it upon reasonable request.

\section{Competing interests}

The authors declare that there is no any conflict of interest regarding the publication of this work.

\section{Funding}

The author(s) received no specific funding for this work

\section{Authors' Contributions}

ZG, FA, GA and HG were participated in designing the study, supervised the data collection, analyzed, interpret and write up the manuscript. FA, GA, HG, AY and TM were involved in proposal development, data collection and entry of data for analysis. TM and ZG are the joint first authors of the paper. All authors read and approved the final drafted manuscript.

\section{Acknowledgements}

The authors would like to acknowledge the study participants, University of Gondar hospital TB clinic and Laboratory staffs for their collaboration. We would also thank to the University of Gondar, College of Medicine and Health Sciences, School of Biomedical and Laboratory Sciences for all the supports and collaborations in general.

\section{References}

1. Mahlangu JN, Davids M. Three-way comparison of methods for the measurement of the erythrocyte sedimentation rate. Journal of clinical laboratory analysis. 2008;22(5):346-52.

2. Ozdem S, Akbas HS, Donmez L, Gultekin M. Comparison of TEST 1 with SRS 100 and ICSH reference method for the measurement of the length of sedimentation reaction in blood. Clinical Chemistry and Laboratory Medicine (CCLM). 2006;44(4):407-12.

3. Musa RJ, Mansoor SS, and, Ali HH. Westergren Sedimentation Rate using K3EDTA. Iranian J Med Sci. 2004;3(2):132-5.

4. Salehzadeh F, Noshin A, Jahangiri S. IVIG effects on erythrocyte sedimentation rate in children. International journal of pediatrics. 2014;2014.

5. Hoffbrand AV, Moss PA. Essential haematology. 6th ed: West Sussex: John Wiley \& Sons; 2011.

6. Dewi MMW, Herawati S, Mulyantari NK, Prabawa IPY. The comparison of erythrocyte sedimentation rate (ESR) modify Westergren Caretium Xc-A30 and Westergren Manual in Clinical Pathology 
Laboratory, Sanglah General Hospital, Denpasar, Bali. Bali Med J. 2019;8(2):396-9.

7. American Society for Clinical Pathology/ American Proficiency Institute. Educational Commentary. The Erythrocyte Sedimentation Rate and its Clinical Utility. $2^{\text {nd }}$ Test Event, 2006. Available at: http://www.api-pt.com/Reference/Commentary/2006Bcoag.pdf. Accessed on December 20, 2019

8. Mack DR, Langton C, Markowitz J, LeLeiko N, Griffiths A, Bousvaros A, et al. Laboratory values for children with newly diagnosed inflammatory bowel disease. Pediatrics. 2007;119(6):1113-9.

9. Kumta S, Nayak G, Kedilaya H P, and, Shantaram M. A COMPARATIVE STUDY OF ERYTHROCYTE SEDIMENTATION RATE (ESR) USING SODIUM CITRATE AND EDTA. International Journal of Pharmacy and Biological Sciences IJPBS. 2011;1(4):393-6.

10. Brigden $M$. The erythrocyte sedimentation rate: still a helpful test when used judiciously. Postgraduate medicine. 1998;103(5):257-74.

11. Go DJ, Lee EY, Lee EB, Song YW, Konig MF, Park JK. Elevated erythrocyte sedimentation rate is predictive of interstitial lung disease and mortality in dermatomyositis: a korean retrospective cohort study. Journal of Korean medical science. 2016;31(3):389-96.

12. Saadeh $C$. The erythrocyte sedimentation rate: old and new clinical applications. SOUTHERN MEDICAL JOURNAL-BIRMINGHAM ALABAMA-. 1998;91:219-26.

13. Brigden ML. Clinical utility of the erythrocyte sedimentation rate. American family physician. 1999;60(5):1443-50.

14. Bain B. Some influences on the ESR and the fibrinogen level in healthy subjects. Clinical \& Laboratory Haematology. 1983;5(1):45-54.

15. Zlonis $\mathrm{M}$. The mystique of the erythrocyte sedimentation rate: a reappraisal of one of the oldest laboratory tests still in use. Clinics in laboratory medicine. 1993;13(4):787-800.

16. Gabay C, Kushner I. Acute-phase proteins and other systemic responses to inflammation. New England journal of medicine. 1999;340(6):448-54.

17. Fabry TL. Mechanism of erythrocyte aggregation and sedimentation. Blood. 1987;70(5):1572-6.

18. Mahalakshamamma V, Raju E, Jhansi K. Erythrocyte Sedimentation Rate Values In Pulmonary Tuberculosis Versus Normal Healthy Peoples In Khammam Region Of Telangana, India. International Journal Of Integrative Medical Sciences. 2016;3:207-10.

19. Mandal SK, Chavan L. Erythrocyte Sedimentation Rate Values in Cases of Active Tuberculosis without HIV Co-Infection. Journal of Medical Science And clinical Research. 2016;4(10):13156-9.

20. Lefrere J, Salmon D, Doinel C, Rouger P, Courouce A, Lambin P, et al. Sedimentation rate as a predictive marker in HIV infection. AIDS (London, England). 1988;2(1):63.

21. Foromera J. Diagnostic and Prognostic Value of ESR and CRP in HIV Positive Adults in Durban, South Africa. Doctoral dissertation, Harvard Medical School.2017".

22. Wolfe F, Michaud K. The clinical and research significance of the erythrocyte sedimentation rate. The Journal of Rheumatology. 1994;21(7):1227-37.

23. Cheesbrough M. District laboratory practice in tropical countries: Cambridge university press; 2006. 
24. Thue G, Sandberg S, Fugelli P. The erythrocyte sedimentation rate in general practice: clinical assessment based on case histories. Scandinavian journal of clinical and laboratory investigation. 1994;54(4):291-300.

25. Horsti J, Kovanen M. Using EDTA as an anticoagulant for ESR to replace citrate. Kliin lab. 2000;4:97100.

26. Koepke J, Van Assendelft O, Bull B, Richardson-Jones A. Standardization of EDTA anticoagulation for blood counting procedures. Labmedica. 1988;1989:5.

27. International Council for Standardization in Haematology. ICSH recommendation for measurement of erythrocyte sedimentation rate. J Clin Pathol. 1993; 46: 198-203.

28. National Committee for Clinical Laboratory Standards. Reference and Selected Procedure for Erythrocyte Sedimentation Rate (ESR) Test; Approved Standard, 4th ed. H2-A4. Villanova, PA: NCCLS; 2000.

29. Jou J, Lewis S, Briggs C, LEE SH, De La Salle B, McFadden S, et al. ICSH review of the measurement of the erythocyte sedimentation rate. International journal of laboratory hematology. 2011;33(2):12532.

30. Central Statistical Agency, Summary and statistical report of the 2007 population and housing census: population size by age and sex, Addis Ababa, Ethiopia, 2008.

31. Emelike O, Akpan J, Obigwe B, Jeremiah Z. Comparative Study of Erythrocyte Sedimentation Rate (ESR) Using Trisodium Citrate, Normal Saline and Whole Blood in Ethylene Di Amine Tetra Acetic Acid (EDTA). Journal of Applied Sciences and Environmental Management. 2010;14(1).

32. Altman DG, Bland JM. Assessing agreement between methods of measurement. Clinical chemistry. 2017;63(10):1653-4.

33. Fischbach FT, Dunning III MB. A Manual of Laboratory and Diagnostic Test. . 9th ed. Philadelphia Wolters Kluwer Health I Lippincott Williams \& Wilkins; 2015.

34. Lawrence JS. Assessment of the Activity of Disease, London: H. K. Lewis \& Co., Ltd., 1961.pp 31-56.

35. Hardwicke J, Squire J. The basis of the erythrocyte sedimentation rate. Clinical science. 1952;11(4):333.

36. Furukawa K, Abumiya T, Sakai K, Hirano M, Osanai T, Shichinohe H, et al. Increased blood viscosity in ischemic stroke patients with small artery occlusion measured by an electromagnetic spinning sphere viscometer. Journal of Stroke and Cerebrovascular Diseases. 2016;25(11):2762-9.

37. Maghsood R, Geransar A, Jahanzad E, Jahanzad L. A comparative study on the effect of sodium citrate and EDTA in ESR after one and two hours in children and adults, Tehran University of Medical Sciences. IJP: 2005: 15 (2).

38. Simtoco MJ, Enricuso CF, Gonzaga WJ., Cabrera NL, Tria MT. Comparison of ESR among patients of Cebu doctors' hospital using EDTA and citrated blood, at Cebu Doctors' Hospital Laboratory. Thesis. Cebu Doctors' University, 1998. 


\section{Tables}

Table 1: Socio-demographic information of the study participants $(\mathrm{N}=70)$

\begin{tabular}{llll}
\hline Characteristics & & Frequency & Percent (\%) \\
\hline Sex & Male & 46 & 65.7 \\
& Female & 24 & 34.3 \\
Age in years & $15 \_25$ & 17 & 24.3 \\
& $26 \_35$ & 18 & 25.7 \\
& $36 \_50$ & 21 & 30 \\
& $>50$ & 14 & 20 \\
Religion & Muslim & 9 & 12.9 \\
& Orthodox & 61 & 87.1 \\
Residence & Rural & 46 & 65.7 \\
& Urban & 24 & 24.3 \\
& & & \\
\hline
\end{tabular}


Table 2: Paired t-test comparing the Mean \pm SD ESR values of the study participants using EDTA and TSC Whole Blood

\begin{tabular}{|c|c|c|c|c|c|}
\hline \multirow[t]{3}{*}{ Variables } & \multirow[t]{3}{*}{ Category } & \multicolumn{2}{|c|}{$\begin{array}{l}\text { Mean and SD of ESR in } \\
\mathrm{mm} / \mathrm{hr}\end{array}$} & \multirow[t]{2}{*}{$\begin{array}{l}\text { Paired } \\
\text { Differences }\end{array}$} & \multirow{3}{*}{$\begin{array}{l}\mathrm{P} \text { - } \\
\text { value }\end{array}$} \\
\hline & & EDTA & TSC & & \\
\hline & & Mean \pm SD & Mean \pm SD & Mean \pm SD & \\
\hline \multirow[t]{2}{*}{ Sex } & M (46) & $59.57 \pm 42.31$ & $53.57 \pm 44.61$ & $6.00 \pm 14.09$ & 0.006 \\
\hline & $F(24)$ & $54.71 \pm 40.44$ & $46.04 \pm 41.82$ & $8.67 \pm 12.92$ & 0.003 \\
\hline \multirow[t]{4}{*}{ Age in year } & $15-25(17)$ & $36.53 \pm 36.07$ & $28.88 \pm 36.26$ & $7.45 \pm 9.99$ & 0.006 \\
\hline & $26-35$ (18) & $56.78 \pm 43.76$ & $47.11 \pm 45.91$ & $9.67 \pm 14.82$ & 0.013 \\
\hline & $36-50(21)$ & $62.52 \pm 43.10$ & $59.90 \pm 45.23$ & $2.62 \pm 13.78$ & 0.394 \\
\hline & $>50(14)$ & $78.36 \pm 32.73$ & $69.43 \pm 37.09$ & $8.93 \pm 15.59$ & 0.052 \\
\hline \multirow[t]{2}{*}{ Residence } & Rural (46) & $54.76 \pm 41.08$ & $47.80 \pm 42.55$ & $6.96 \pm 14.83$ & 0.003 \\
\hline & Urban (24) & $63.92 \pm 42.36$ & $57.08 \pm 45.61$ & $6.83 \pm 11.38$ & 0.007 \\
\hline \multirow{2}{*}{$\begin{array}{l}\text { Previous TB } \\
\text { History }\end{array}$} & Yes (17) & $69.71 \pm 41.20$ & $65.00 \pm 43.86$ & $4.71 \pm 16.60$ & 0.260 \\
\hline & No (53) & $54.11 \pm 41.20$ & $46.49 \pm 42.85$ & $7.62 \pm 12.68$ & 0.000 \\
\hline \multirow[t]{2}{*}{ TB Status } & Positive (7) & $88.71 \pm 24.40$ & $82.57 \pm 39.94$ & $6.14 \pm 16.29$ & 0.357 \\
\hline & $\begin{array}{l}\text { Negative } \\
(63)\end{array}$ & $54.48 \pm 41.65$ & $47.48 \pm 42.76$ & $7.00 \pm 13.49$ & 0.000 \\
\hline \multicolumn{2}{|l|}{ Total } & $57.90 \pm 41.45$ & $50.99 \pm 43.52$ & $6.91 \pm 13.66$ & 0.000 \\
\hline
\end{tabular}

$\mathrm{SD}=$ standard deviation

\section{Figures}




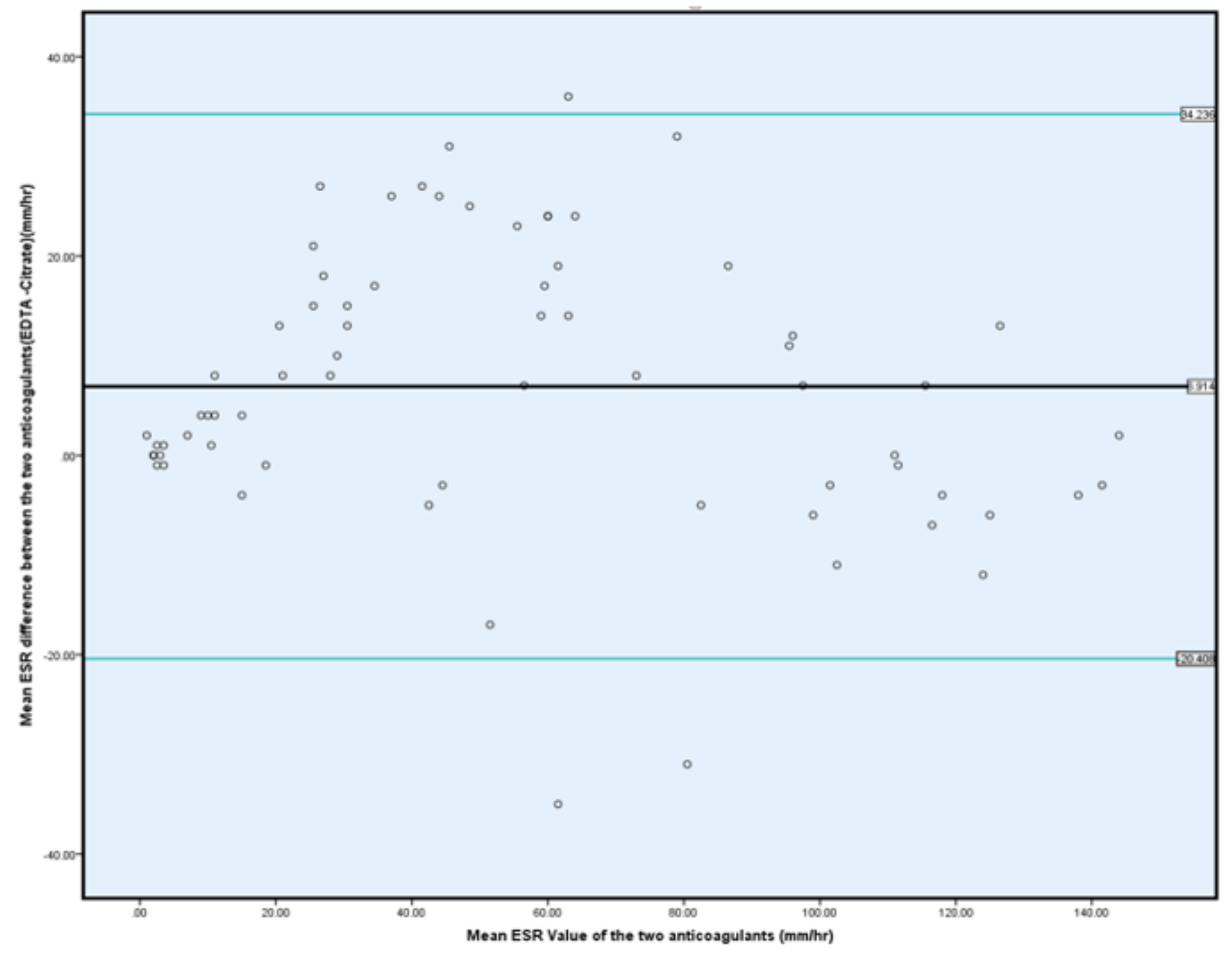

Figure 1

Bland-Altman plot of ESR values from the EDTA and the TSC whole blood using manual Westergren method

\section{Supplementary Files}

This is a list of supplementary files associated with this preprint. Click to download.

- Methodsformula.docx

- Additionalfiles.docx 